\title{
The Metacognitive Strategy in English Listening Comprehension
}

\author{
Jie Zheng \\ Foreign Language Department, Sichuan Vocational and Technical College, Suining, Sichuan, China
}

\begin{abstract}
It is of vital importance that our students should be taught to listen effectively and critically. However, listening is a highly complex, interactive process. This essay focuses the listening comprehension and the metacognitive strategy in listening in order to provide a new angle from which listening teaching is explored to help not only different proficient students but also the English teachers.
\end{abstract}

Index Terms-English listening comprehension, metacognitive strategy, different proficient learners

\section{INTRODUCTION}

Contemporary society exhibits a shift from the "exam-oriented education" to "education for all-round development and innovation". Nowadays, it is of great importance that our students should be taught to listen effectively and critically. National English Curriculum Standards (2001, pp. 3), a syllabus formulated by the Chinese Ministry of Education, rules that English listening is an indispensable part in English teaching and no less than 20\% of English test contents should be on it.

However, few studies have been concerned with listening comprehension process and listening instruction. Thus, listening remains one of the least understood processes in language learning (Morley, 1991, pp. 75). Thus, this essay will focus the listening comprehension and the metacognitive strategy in listening.

\section{LISTENING COMPREHENSION}

In 1996, the International Listening Association gave a definition to the listening comprehension: listening is a process of receiving and constructing meaning forms and a process of reacting to verbal and nonverbal information (Carrier, 1999, pp. 73). Date back to 1976, Kenneth thinks listening comprehension constitutes five compositions, and one composition always depends on another one, that is, discrimination, the perception of message, the use or store message, the auditory memory and the decoding message. Besides these compositions, Abbott (1981, pp. 135) advocates that the foreign language comprehension procession has also link with people's mother tongue. He points out that listening comprehension includes feeling to know, decoding, prediction, and choice. As listening has often been called a passive skill, in 1984, Thomlinson defines listening as "active" which goes beyond comprehending literally to an empathetic understanding of the speaker (Carrier, 1999). Ronald and Roskelly (1986, pp. 243) also define listening as an active process requiring the same skills of prediction, hypothesizing, checking, and revising.

Based on the previous definitions, Michael Rost (2002, pp. 167) comprehensively summarizes the definition of listening comprehension in Teaching Listening Comprehension, it shows the four orientations, the receptive, the constructive, the collaborative and the transformative. Metacognitive strategy is mainly based on the orientations of listening comprehension, thus, these four orientations are illustrated in detail.

On the basis of researches by many scholars, O' Mally and Chamot (1989, pp. 434) state that listening comprehension is an active and conscious process in which the listener constructs meaning by using cues from contextual information and existing knowledge, while relying upon multiple strategic resources to fulfill the task requirement. Vandergrift also holds the same view. He states in detail, "Listening comprehension is a complex, active process in which the listeners must discriminate between sounds, understand vocabulary and grammatical structures, interpret stress and intonation, retain what was gathered in all of the above, and interpret it within the immediate as well as the larger social structural context of the utterance. Coordinating all these involves a great deal of mental activities on the part of listener" (1990, pp. 174).

Receptive listening refers to the fact that the listener receives the utterance the speaker actually expresses. Specially, listening is to catch the words the speaker says, grasp his or her thought, decipher the information, divide the content and get the shift of speakers' images, impressions, ideas, beliefs, emotions and attitudes. Under this view, listening is conventionally referred to as a receptive skill. Being receptive does not, however, mean being passive. Listening is in fact a highly active process (Ronald\& Roskelly, 1985; O' Mally\& Chamot, 1989; Vandergrift, 1997; Michael Rost, 2002). For reorganizing speaker's intentional message, the hearer has to positively utilize the knowledge linguistically and nonlinguistically. The linguistic source includes the following items such as vocabulary, syntactic and phonetic problems. The nonlinguistic source refers to background knowledge. Hearer can recognize the continuous sound as meaningful units at all only by applying his knowledge of the language, and he can interpret the meaning only by 
comparing these units with the shared knowledge between himself and the speaker. In fact, the majority of utterances that we hear in daily life could be seen as carrying different meanings in different circumstances, and it is only because we are actively involved in the communication process that we are generally able to relate them to single appropriate meaning. If the listener failed to process the linguistic signals, he would also fail to understand the meaning. But it is very hard for the hearer to realize his misunderstanding when he continues non-stoply to involve himself in the communication, not making him distracted by sense of failure by means of using the linguistic clues and nonlinguistic knowledge. He'd better be aware that some clues are less important than others in the message. Hence, even he doesn't know some pieces of language, he should be told not to be panic as he is capable of making use of other clues to understand the message to achieve his basic purpose better.

In the light of constructive view, listening means constructing and representing meaning. Especially, listening signifies that the hearer should look for interesting things in speaker' words, find out the most relevance, reconstruct the relevant information from speaker's message and understand the strategy of speaker's way of expressing.

In the light of collaborative view, listening means negotiating meaning with the speaker on the choice of a code and a context and responding. In particular, listening refers to the response to the speakers' utterance, the process of sharing ideas or information with the speaker, active participation in speaker's talk and react to the speaker whether you grasp his idea or not.

Transformative listening means the creation of the meaning by means of imagination, involvement and empathy. Especially, listening can not only be understood as the creation of the connection between the speaker and the listener, of the empathy with speaker's motivation as he speaks, of a process of meaning making in the communication, but also as the accomplishment of communication, the consciousness feeling when the hearer pay concern to things and the process of changing the cognitive environment of both the speaker and the listener.

It can be easily seen that in the last three perspectives of listening, the key concept is meaning, the understanding of which is the main purpose of listening comprehension.

\section{METACOGNITIVE STRATEGY}

Metacognitive strategy are those used to manage, plan and evaluate the use of cognitive strategy. In other words, They ask the listener to make a plan for learning, think about the occurring learning process, monitor the production and comprehension dynamically and evaluate the learning upon the finish of an activity. It has rarely been applied to the research in listening instruction. It is this dearth of such listening instruction research that inspired the present study, which is just where the significance of this study lies.

According to Flavell, metacognitive knowledge plays an important role in many cognitive activities related to language use, e.g. oral comprehension or communication of information, reading comprehension, and writing, to language acquisition, and to various types of self-instruction (Flavell, 1979, pp. 906). Existence of metacognitive knowledge provides basis for metacognitive experience. While for regulation (metacognitive strategy) to happen, the learner is usually aware of being going to be involved in metacognition.

Brown and Palincsar, when commenting in the failure of strategy training to transfer to new learning activities, noted "much of this difficulty could be attributed to the failure to combine metacognitive strategy with cognitive strategy during learning (Brown,1982, pp. 46)."

In 1990, Oxford made a diagram of metacognitive strategy system. In his system, there are three parts, centering learning, arranging and planning and evaluating, in metacognitive strategy. The first part, centering learning, includes over viewing and linking with known, paying attention and delaying speech production to focus on listening. In arranging and planning process, learner finds out about language learning, organizes, sets goals and objectives, identifies the purpose of a language task, plans for a language task and seeks practice opportunities. The last part, evaluating, is self-monitoring and self-evaluating. Vandergrift (1999, pp. 390) concludes metacognitive strategy include overviewing and linking, setting objectives, planning, monitoring and evaluating. Overviewing and linking means that the learner takes a comprehensive viewing on a key concept, rule, or set of linguistic materials to learn the purpose of the conversation, to memorize vocabulary, and make associations. For instance, before a chapter in an English textbook, the learner should look through the whole chapter about its vocabulary, grammar, purpose, arrangement, etc. This will promote the learner a lot and make the reading more effective and efficient. After objectives are set, a learner can choose objectives, such as short term, mid-term and long-term. Planning is to predict and learn the basic language for an upcoming language task. For instance, before giving a call to the airline ticket agency, one can practice the conversation in advance. In monitoring, the learner will make an effort to notice and correct the mistakes with the language skills. For example, the learner should write down the difficulties with the language and then asks the teacher or native speaker for help. This skill must always be used without killing communication. It is an efficient way to learn from mistakes, rather than avoid mistake-making. Evaluating means evaluating the whole progress or progress in any of the four skills. One can use a tape recorder to evaluate speech or pay concern to how natives are responding to the words to check the understanding.

Based on the researches before him, Zheng Min (2000, pp. 12), puts forward a classification scheme on the basis that many areas involve metacognition, even including social interaction. Her classification scheme emphasizes the significance of metacognitive strategy and clearly suggests metacognitve strategy is of higher order. She claims that 
self-monitoring plays a dominant role in human beings' thinking system and many researchers in language learning strategy have confirmed the importance of metacognitive strategy. However, in Zheng' $\mathrm{s}$ classification, the metacognitive strategy only refers to "monitoring" while metacognitive strategy in O' Malley and Chamot's classification consist of several subcategories such as advance attention, self-evaluation, self-management etc.

However, a number of factors are assumed to affect the use of metacognitive strategy. These factors should not be ignored. With to students of the same cultural background, their use of metacognitive strategy is mainly influenced by the following factors. First is the learner's proficiency of the target language. It shows by some qualitative analyses that effective foreign language students are purposeful in their approach to a task, monitored their comprehension, and effectively used their prior knowledge while working on a task (O'Mally\&Chamot, 1990, pp. 140-141). Second factor is task requirements. It has been found that the complexity of a language is related to the frequency of strategy use. When the language task is difficult, learners tend to use metacognitive strategy mostly in order to ensure a success. When the task is too easy learners need not to use metacognitive strategy. For sometimes it does not require a cognitive process, let alone metacognitive process. Next one is the learners' individual differences such as attitude, motivation, age, personality, gender, general learning style, aptitude, etc. Although learners' individual differences also have great effect on the use of metacognitive strategy, some of these differences can not be changed such as age and gender are difficult to change, as well as learning style aptitude and personality. But on the other hand, most studies which test the effect of motivation have found a strong correlation between the motivation and language learning success. In reviewing the effect of different factors on the development of learning strategy, Oxford and Nyikos (1989, pp. 291) conclude that motivation appears to correlate best with strategy and that increased motivation and self-esteem led to more effective use of appropriate strategy and vice versa. So during the strategy training, teacher should try every means to motivate his students so as to ensure the smooth development of students' use of metacognitive strategy.

O' Malley and Chamot give a detailed division of metacognitive strategy. Among the main metacognitive strategy, Advance Organizers refers to the making of a general but comprehensive preview of the organized concept or principle in an anticipated learning activity; Directed attention is decided in advance to attend in general to a learning task and to ignore irrelevant distracters. Selective attention is decided in advance to attend to specific aspects of language input of situational details which will cue the retention of language input. Self-management means understanding the conditions which helps one to learn and arrange for the presence of those conditions. Advance preparation is the preparing for and rehearsing linguistic components necessary to carry out and upcoming language task. Self-monitoring is correcting one's speech for accuracy in pronunciation, grammar, vocabulary, or for appropriateness related to the setting or to the people who are present. Delayed production is consciously decided to postpone speaking in order to learn initially through listening comprehension; self-evaluation means checking out one's outcome of one's own language learning against an internal measure of completeness and accuracy and lastly, self-reinforcement is giving oneself rewards for success.

\section{Metacognitive Strategy In Listening Comprehension}

Christine (2002, pp. 185) conducts a study in Singapore to examine a group of Chinese ESL learners' listening strategy and the tactics that operationalised these strategy. He collects data by using a retrospective verbalization procedure. The study reveals that both effective and ineffective listeners make use of prior knowledge, text and context but the effective listeners use more inferencing, comprehension monitoring and comprehension evaluation strategy than ineffective listeners. At the same time the study shows the hierarchic relationships between strategy behaviors during listening. Dreyer and Oxford (1996, pp. 145) study the correlation of strategy use of Afrikaans at the Potchefstroom University and ESL proficiency represented by TOEFL score. The study finds significant correlation with metacognitive strategy ranking first $(\mathrm{r}=.64, \mathrm{p}<.001)$. Studies focusing on reading, writing and vocabulary acquisition more or less reveal the correlation between metacognitive strategy use and its respective proficiency.

In 1984, Huang Xiaohua finished her postgraduate thesis named "An investigation of learning strategy in oral communication that Chinese EFL learners in China employ"(Huang, 1985). In 1985, she and her tutor published the thesis "Learning strategy for oral communication" in "Applied Linguistics", which is the first paper concerning learning strategy published on the international journal in China. This study reviewed the relation between the use of strategy and the oral level of the senior English-majors. Chen (1990) published on "Language learning" "A study of communication strategy in inter-language production by Chinese EFL learners". This research described the frequency, types and the validity of strategy used by English-majors. In the late 1980's, Wu Yian made a most comprehensive survey on the Chinese English-majors. In this project, they list learning strategy as one of factors that influence the English performance and published "A study of the quality of Chinese English-majors" in "Foreign Language Teaching and Research". In 1995 Wen Qiufang studied learning concept and strategy of non-English-Majors. In 1997 she made a both qualitative and quantitative study, titled as "The Change of the Concept and Strategy of English-Majors". In 1996 she published a book named "The Theory of English Learning Strategy". Hu (1997) once reported listening strategy training in Northwest Industrial University. As to the specific procedure, the author only gave very simple description: part of the class time would be made use for strategy training for the experimental class while control class would be made use of the class time listening to the material repeatedly.

There is difference among the different proficient learners. Vandergrift (1997, pp. 387) looked at the strategy used by 
learners of different grades in some high schools in Canada learning French. His sample is composed by students in their first, second and fifth years of French language study (called novice) and students in their eighth year of study (called intermediate). He found that novice listeners relied heavily on elaboration, inference and transfer to grasp meaning, and that they overcame their limited knowledge of words by using encyclopedic knowledge. At the intermediate level, he found the students employ metacognitive strategy much than at the novice level in which they use predominant use of cognitive strategy, especially elaboration and inference. In this study, it is found that the largest percentage of the strategy reported by the subjects is cognitive strategy. The results of this study also suggest that the biggest difference between successful and less successful learners seems to lie in the use of metacognitive strategy. The successful listeners are better at employing metacognitive strategy to facilitate their cognitive processing of input information. On the other hand, the less effective listeners lack the regulating control of metacognitive strategy to help them in efficient comprehension. He Xin (2007, pp. 25) found that the high-level learners are good at using such metacognitive strategy as inferring, pre-listening skimming, getting familiar with the different listening material, i.e. using the encyclopedic knowledge to predict the difficult parts and identify the key words to work out the motif; the adjustment of attention, etc. His questionnaire reveled that high level students use metacognitive strategy more frequently than the low level students.

In 1998, Huang Zidong (1998, pp. 46) concluded eight representatives of listening strategy research abroad. In 1987, Murphy found advanced students pay more attention to "individualization", inferencing, self-description and making hypotheses than poor students are inclined to use discourse strategy by researching college students enrolled in ESL classes at intermediate level. With the same level of students, O' Malley (1989) concluded that the principal strategic resources students deployed to aid in comprehension self-monitoring, elaboration and inferencing differentiate effective students from ineffective ones. Application of strategy is closely related to the phases of listening comprehension. The forth one is from Laviosa (1991). He studied five proficient students of learning Italian to find that each subject varies greatly in using listening strategy and the strategy used by students are closely related to each other. The sixth is Vandergrift's research on French learners (1990). Elementary level students mainly use cognitive strategy such as elaboration, transfer and inferencing; intermediate level students not only use above cognitive strategy but also use other metacognitive strategy. Bacon' study in 1992 is the seventh representative of listening strategy research. The subjects are fifty Spanish learners with English as native language. He found that students' application of listening comprehension strategy changes in accordance with the sequence and difficulty if discourse, but the change doesn't distinctively affect comprehension. Girls are better than boys at using various metacognitive strategy and can adjust better to the difficult discourse. However, girls are more mechanical in using cognitive strategy while boys are quite flexible in using some cognitive strategy. The last representative is Vogely's (1995). By studying eighty-three Spanish students, he concluded that students in first semester are best at recollecting the task and can apply various strategy more effectively, the following groups are students in third and forth semester, the second semester are worst.

Influenced by the westerns' study, the research in China about metacognition becomes more mature. China National Knowledge Infrastructure (CNKI), which was found in 1995, is the biggest database in China. According to CNKI, there are about 714 articles about metacognition. 569 articles are in Chinese Journal Full-text Database (CJFD) and 145 are in Chinese Selected Doctoral Dissertations and Master's Theses Full-text Databases (CDMD). The number of articles in metacognition is increasing in five years from 2002 to 2006 and most of them are published in different kinds of journals. Though metacognion is a word in psychology, there are few in psychological journals. Because more and more researchers from different fields take part in research about metacognition, many new thoughts emerge and can be searched. From the perspective of research objects, there are children, pupils, students of high school, successful university students, unsuccessful university students, adults and teachers. However, the focus are still student and many researches bring good effects in improving students' learning and thinking on one' s own ability and help to achieve the learning goal. From the perspective of research field, there are metacognitive researches under multi-media condition, metacognitive contrast research, research about the relationship between metacognition and thinking quality and so on. From the perspective of teaching work, there are the researches of metacognition in mathematics, physics, chemistry, Chinese and English.

$\mathrm{Li}$ (2002) conducts a research and finds out a significant correlation between language proficiency and metacognitive strategy ( $\mathrm{r}=.300)$. Yang and Zhang (2002) conduct a study focusing on metacognitive strategy in terms of its influence on reading proficiency. Using a self-designed questionnaire, the study shows a significant correlations between metacognitive strategy and reading proficiency $(\mathrm{r}=.42$, $\mathrm{p}<.01)$. Su Yuanlian (2003, pp. 1) uses a self-designed questionnaire and a training course to investigate the effect of listening learning strategy instruction on Chinese EFL beginners' listening comprehension performance. As to the above mentioned, although there have been a deal of studies on the strategy use and language performance, there is little experimental research with attention to listening strategy, not mention research focusing on metacognitive strategy and the experimental research of metacognitive strategy in primary English listening.

O' Malley and Chamot point out that those students without metacognitive approaches are essentially learners without direction and ability to review their process, accomplishments and failure learning directions (O' Malley, 1985, pp. 557). Brown and Palincsar, when commenting in the failure of strategy training to transfer to new learning activities, noted "much of this difficulty could be attributed to the failure to combine metacognitive strategy with cognitive 
strategy during learning (Brown, 1982, pp. 46).” Peter Skehan (1998, pp. 38) notes that reflection, monitoring and evaluation are the key factors in applying learning strategy. Without them what the learners acquire are just some scattered learning techniques which are not helpful in the whole process of learning. It was also revealed in Wen Qiufang's (1996) individual case study that good learners display extraordinary ability in macro or micro management of their learning process. They frequently reflect upon and evaluate their achievements in learning process. And, the ability of manipulating the cognitive process is one of the essential skills that teachers can teach and help the second language learners develop.

\section{CONCLUSION}

Listening is a highly complex, interactive process. With the review of the related literature, the success of listening, to a great extent, depends on the use of metacognitive strategy. In conclusion, this thesis provides a new angle from which listening teaching is explored. It is expected that this study could help not only the students but also the English teachers.

\section{ACKNOWLEDGEMENTS}

This research was financially supported by the Fund Project of Education Department of Sichuan Province. (The Application of Dynamic System Theory in English and Chinese Attrition, NO. 16SB0293)

\section{REFERENCES}

[1] Abbott, G. (1981). The Teaching of English as an International Language: A Practical Guide. Glasgow and London: Collins.

[2] Bacon, S. (1992). The relationship between gender, comprehension, processing strategies, and cognitive and affective response in foreign language listening. The Modern Language Journal, 76, 160-178.

[3] Brown, A. L. \& Palincsar, A. S. (1982). Inducing strategies learning from tests by means of informed, self-control training. Topics in Learning Disabilities, 2 (1), 1-17.

[4] Carrier, K. (1999). The social environment of second language listening: Status plays a role in comprehension? The Modern Language Journal, 83 (1), 65-79.

[5] Chen, S. Q. (1990). A study of communication strategies in inter-language production by Chinese EFL learners. Language Learning. 6, 155-187.

[6] Christine, C. M. (2002). Exploring listening comprehension tactics and their interaction pattern. System, 30, 185-206.

[7] Dreyer, C. \& Oxford, R. L. (1996). Learning strategies and other predictors of ESL proficiency among Afrikaans speakers in South Africa. In R. L. Oxford (Eds.). Language Learning Strategies around the World: Cross-Cultural Perspectives. Honolulu: University of Hawaii's Second Language Teaching \& Curriculum Center.

[8] Flavell, J. H. (1979). Metacognition and cognitive monitoring: A new area of cognitive developmental inquiry. American Psychologist, 34, 906-911.

[9] He Xin. (2007). The research on metacognitive strategies training in college English listening course. Master essay. Liaoning Normal University.

[10] Hu Yinghui. (1997). Analysis of learning strategies in listening understanding. Shandong Foreign Language Teaching Journal, 3, 80-84.

[11] Huang Xiaohua \& Margaret Van Naerssen. (1987). Learning strategies for oral communication. Applied Linguistics, 18 (3), 287-307.

[12] Huang Zidong. (1998). On the Second/ Foreign Language Listening Comprehension Strategies. Foreign Language World, 1, 45-48.

[13] Kenneth, C. (1976). Developing Second Language Skills: Theory to Practice. Houghton Company, The Center for Curriculum Development.

[14] Laviosa, F. (1991). An Investigation of the Listening Strategies of Advanced Learners of Italian as a Second Language. Paper, Bridgeing Theory and Practice in the Foreign Language Classroom. MD: Loyola College.

[15] Li Jiongying. (2002). The Concept and Application of Second Language Leaning Strategies for Chinese Learners. Foreign Language Education, 1, 42-49.

[16] Morley, J. (1991). Listening comprehension in second / foreign language instruction. In Celce-Murcia, M (Eds.), Teaching English as a second or foreign language. Boston: Heinle and Heinle.

[17] Murphy, D. (1987). Offshore education: A Hong Kong Perspective. Australian Universities Review, 30 (2), 43-44.

[18] National English Curriculum Standards. (2001). Beijing: Beijing Normal University Publishment.

[19] O’ Malley, J. M. \& Chamot, A. U. (1985). Learning Strategy Applications with Students of English as a Second Language. TESOL Quarterly, 19, 557-584.

[20] O' Malley, J. M. \& Chamot, A. U. (1989). Listening comprehension strategy in second language acquisition. Applied Linguistics, 10, 418-435.

[21] O' Malley, J. M. \& Chamot, A. U. (1990). Learning Strategies in Second Language Acquisition. Cambridge: Cambridge University Press.

[22] Oxford, R. L. \& Nyikos, M. (1989). Variables affecting choice of language learning strategies by university students. The Modern Language Journal, 73,291-300.

[23] Oxford, R. L. (1990). Language learning strategies: What every teacher should know. Boston; Heinle \& Heinle.

[24] Ronald, K. \& Roskelly, H. (1986). Listening as an act of composing. Journal of Basic Writing, 15 (2), 28-40.

[25] Rost, M. (2002). Teaching and Researching listening. Beijing: Foreign Language Teaching and Research Press. 
[26] Skehan, P. (1998). A Cognitive Approach to Language Learning. Oxford: Oxford University Press.

[27] Su Yuanlian. (2003). On the Teachability of Listening Learning Strategies---An Test on Chinese Novice Foreign Language Learner. Modern Foreign Languages, 1, 48-58.

[28] Vandergrift, L. (1990). Facilitating Second Language Listening Comprehension: Acquiring Successful Strategies. ELT Journal, 53, 168-176.

[29] Vandergrift, L. (1997). The comprehension strategies of second language (French) listeners: a descriptive study. Foreign Language Annals, 30, 387-490.

[30] Vandergrift, L. (1999). Facilitating second language listening comprehension: Acquiring successful strategies. English Language Teachers Journal, 53 (3), 168-175.

[31] Vogely, A. (1995). Perceived strategy use during performance on three authentic listening comprehension tasks. Modern Language Journal, 79 (1), 41-55.

[32] Wen Qiufang. (1995). The Differences Between Successful and Failing English Learners. Foreign Language Teaching and Research, 3, 61-66.

[33] Wen Qiufang. (1996). The Theory of English Learning Strategy. Shanghai: Shanghai Foreign Language Education Press.

[34] Wu Yian. (1989). A study of the quality of Chinese English-majors. Foreign Language Teaching and Research, 21 (1), 3-12.

[35] Yang Xiaohu \& Zhang Wenpeng. (2002). The Relevant Research on the Metacognition and English Reading Comprehension for Chinese Students. Foreign Language Teaching and Research, 3, 213-218.

[36] Zheng min. (2000). Doubts on the classification framework of language learning strategies. Foreign Languages and Their Teaching, 12, 33-35.

Jie Zheng was born in Chongqing, China in 1983. She received her Master's degree in English Teaching Methodology from Sichuan International Studies University, China in 2009.

She is currently a Lecturer in the Foreign Languages Department, Sichuan Vocational and Technical College, Suining, Sichuan, China. Her research interests include Applied Linguistics and Teaching Methodology. 